NASA Technical Memorandum 101973

\title{
Three Dimensional Thermal Analysis of Rocket Thrust Chambers
}

\author{
(BASA-TH-101973) THREE DIEEISICMAL TBBREAL N89-21025 \\ IDALYSIS CF ECCRET THECST CELEERS (MASA) \\ $3 \Xi F$ \\ CSCL $21 \mathrm{H}$ \\ $\begin{array}{ll} & \text { Onclas } \\ 63 / 20 & 0198640\end{array}$
}

\author{
M.H.N. Naraghi \\ Manhattan College \\ Riverdale, New York \\ and \\ E.S. Armstrong \\ Lewis Research Center \\ Cleveland, Ohio
}

Prepared for the

Thermophysics, Plasmadynamics and Lasers Conference

sponsored by the American Institute of Aeronautics and Astronautics

San Antonio, Texas, June 27-29, 1988 


\title{
THREE DIMENSIONAL THERMAL ANALYSIS OF ROCKET THRUST CHAMBERS
}

\author{
M.H.N. Naraghi \\ Department of Mechanical Engineering \\ Manhattan College \\ Riverdale, New York 10471 \\ and \\ E. S. Armstrong \\ National Aeronautics and Space Administration \\ Lewis Research Center \\ Cleveland, Ohio 44135
}

\begin{abstract}
Summary
A numerical model for the three dimensional thermal analysis of rocket thrust chambers and nozzles has been developed. The input to the model consists of the composition of the fuel/oxidant mixture and flow rates, chamber pressure, coolant entrance temperature and pressure, dimensions of the engine, materials and the number of nodes in different parts of the engine. The model allows for temperature variation in three dimensions: axial, radial and circumferential directions and by implementing an iterative scheme, it provides nodal temperature distribution, rates of heat transfer, hot gas and coolant thermal and transport properties.
\end{abstract}




\section{Nomenclature}

$\begin{array}{ll}A & \text { area of the nozzle } \\ C & \text { correction factor for heat transfer coefficient } \\ C_{p} & \text { specific heat } \\ C C H & \text { cooling channel height } \\ C C W & \text { cooling channel width } \\ d & \text { diameter of the thrust chamber } \\ D & \text { characteristic diameter } \\ D C I N & \text { distance between bottom of the cooling } \\ & \text { channel and inner surface (see Fig. 3) } \\ D G & \text { gas side diameter } \\ f & \text { friction factor } \\ \text { FO\% } & \text { fuel/oxidant percentage } \\ h & \text { heat transfer coefficient } \\ i & \text { enthalpy } \\ k & \text { conductivity } \\ L & \text { characteristics length } \\ m & \text { total number of stations } \\ P & \text { pressure } \\ P r & \text { Prandtl number } \\ r & \text { radius } \\ R e & \text { Reynolds number } \\ T & \text { temperature } \\ T H K N S & \text { wall thickness } \\ V & \text { velocity } \\ W & \text { weight flow } \\ & \end{array}$




$X \quad$ station position in longitudinal direction
(distance from the rocket throat)

Greek Symbols

$\Delta S \quad$ length of cooling channel between two stations

$\mu \quad$ dynamic viscosity

$\rho \quad$ density

$\underline{\text { Subscripts }}$

$\begin{array}{ll}A & \text { adiabatic } \\ C & \text { coolant } \\ G & \text { gas } \\ n & \text { station } n \\ S & \text { static } \\ W & \text { wall } \\ X & \text { reference } \\ 0 & \text { stagnation }\end{array}$




\section{Introduction}

The thermal analysis of spacecraft engines is an essential step in determining the rate of heat transfer from combustion gases to the coolant and in evaluating thermal stresses due to temperature gradients. In the past, rocket engines werc designed to be used only once; therefore fatigue due to thermal stresses was not an issue and there was no need for an accurate evaluation of temperature gradients. However, in the new reusable spacecraft engines such as SSME (Space Shuttle Main Engine), OTVE (Orbit Transfer Vehicle Engine) and HLLV (Heavy Lift Launch Vehicle), reducing fatigue due to thermal stresses is an important factor in increasing the life of the engine.

The existing thermal model at NASA Lewis Research Center uses a uniform wall temperature assumption in both radial and circumferential directions. This assumption is reasonable as long as the hot gas pressure and temperature gradient are relatively smail. However, in the new engines such as orbit transfer vehicle engines, the gas pressure and temperature gradients are relatively large and the chamber wall includes ribs, fins, and high $L / D$ coolant passages, which make a uniform wall temperature an unreasonable assumption. Existing thermal computer codes such as CINDA/SINDA [1], ADINAT [2], MARC [3], ANSYS [4] and NASTRAN [5] cannot be used without major modifications because of the complex: nature of the problem. The complexity of the problem is due to three-dimensional geometry, coolant, and hot gas heat transfer coefficient dependence on the pressure and wall temperature, and unknown coolant pressure drop and properties. Therefore, a new thermal model, accounting for the complexities of the problem. nceds to be developed. 
The objective of this paper is to explain the numerical model developed to analyze rocket engine heat transfer characteristics. This model can be used to determine the temperature distribution in a regeneratively cooled thrust chamber by allowing for temperature variations in the radial, circumferential, and axial directions.

\section{Numerical Model}

The geometry of a typical regeneratively cooled thrust chamber is shown in Figure 1. The combustion chamber and nozzle wall consists of three layers made of ceramic coating, copper, and nickel with a number of cooling channels (layers of materials may change for different engines). The conductivities of the wall materials can be functions of the wall temperature. A numerical procedure for solving this problem is developed. In this procedure, the rocket thrust chamber and nozzle are subdivided into a number of two-dimensional stations along the longitudinal direction (see Figure 2). The thermodynamic and transport properties of the combustion gases are evaluated using the computer program developed by Gordon and McBride [6-7]. The GASP [8] or WASP [9] programs are implemented to obtain coolant thermodynamics and transport properties. First the static pressures, temperatures and enthalpies for the combustion gases are evaluated using the ROCKET subroutine given in [6]. At a given station, by making an initial guess for the temperature distribution, the gas and coolant adiabatic wall temperatures and wall properties can be evaluated based on the assumed wall temperature

distribution using the computer properties codes [6-9] for combustion gases and coolant. The reference enthalpy of the gas side, $i_{G X}$ is given by

$$
i_{G X}=0.5\left(i_{G W}+i_{G S}\right)+0.180\left(i_{G O}-i_{G S}\right)
$$


where $i_{G W}$ is a function of gas static pressure $P_{G S}$ and gas side wall temperature $T_{G W}$ and is evaluated using the program given in [6]. The gas side adiabatic wall enthalpy, $i_{G A W}$ is calculated using the following equation [10-11]

$$
i_{G A W}=i_{G S}+\left(P r_{G X}\right)^{1 / 3}\left(i_{G O}-i_{G S}\right)
$$

where the gas reference Prandtl number $\operatorname{Pr}_{G X}$ is

$$
\operatorname{Pr}_{G X}=\frac{C_{p_{G X}} \mu_{G X}}{k_{G X}}
$$

$C_{p_{G X}}, \mu_{G X}$ and $k_{G X}$ are functions of $P_{G S}$ and $i_{G X}$. The hot gas side heat transfer coefficient, $h_{G}$ is given by

$$
h_{G}=\frac{C_{G_{n}} k_{G X}}{d_{G_{n}}} \operatorname{Re}_{G X}^{0.8} \operatorname{Pr}_{G X}^{0.3}
$$

where $C_{G_{n}}$ is the gas side correlation coefficient and the Reynolds number is given by

$$
\begin{aligned}
R e_{G X} & =\frac{4 W_{G}}{\pi d_{G_{n}} \mu_{G X}} \frac{T_{G S}}{T_{G X}} \\
T_{G X} & =f\left(P_{G S}, i_{G X}\right) \\
T_{G S} & =f\left(P_{G S}, i_{G S}\right)
\end{aligned}
$$

For the cooling channel the coolant velocity is calculated from the following equation:

$$
V_{C S_{n}}=\frac{W_{C}}{\rho_{C S_{n}} A_{C_{n}} N_{n}}
$$

Note that the coolant static density for the first iteration is set equal to the coolant static density of the previous station and at the first station it is set equal to its stagnation density. The static enthalpy is then calculated using the following equation:

$$
i_{C S_{n}}=i_{C O}-\frac{V_{C S_{n}}^{2}}{2}
$$


The coolant stagnation enthalpy given in the right hand side of equation (5) is a function of the coolant stagnation temperature and pressure, i.e.,

$$
i_{C O_{1}}=f\left(T_{C O_{1}}, P_{C O_{1}}\right)
$$

for the first station and for the other stations it is given by

$$
i_{C O_{n}}=i_{C O_{n-1}}+\frac{\left(q_{n}+q_{n-1}\right) \Delta S_{n-1, n}}{2 W_{C}}
$$

where $\Delta S_{n-1, n}$ is the distance between two neighboring stations $n-1$ and $n$ which is calculated from

$$
\Delta S_{n-1, n}=\sqrt{\left(\frac{d_{G_{n}}-d_{G_{n-1}}}{2}\right)^{2}+\left(x_{n}-x_{n-1}\right)^{2}}
$$

and $q_{n}$ is the heat transferred from the hot gases to the coolant at station $n$. For the first iteration at station $\mathrm{n}, q_{n}$ in equation (7) is not known; therefore the following equation is used to evaluate the stagnation enthalpy

$$
i_{C O_{n}}=i_{C O_{n-1}}+\frac{q_{n-1} \Delta S_{n-1, n}}{W_{C}}
$$

The coolant static and reference Reynolds numbers respectively are given by

$$
\operatorname{Re}_{C S}=\frac{W_{C} d_{C_{n}}}{A_{C_{n}} N_{n} \mu_{C S}}
$$

and

$$
\operatorname{Re}_{C X}=\operatorname{Re}_{C S}\left(\frac{\rho_{C W}}{\rho_{C S}}\right)\left(\frac{\mu_{C S}}{\mu_{C W}}\right)
$$

where $\mu_{C S}$ is a function of $P_{C S}$ and $i_{C S}$ and is calculated using the GASP program [8], or the WASP program [9] if the coolant is water. To employ a better value for the Reynolds number an average Reynolds number between the entrance and exit to each station is evaluated, i.e.,

$$
\operatorname{Re}_{C S_{\text {Avg. }}}=0.5\left(R e_{C S_{n}}+\operatorname{Re}_{C S_{n-1}}\right)
$$




$$
R e_{C X_{A v g,}}=0.5\left(R e_{C X_{n}}+R e_{C X_{n-1}}\right)
$$

The friction factor in the cooling channel is calculated using the Moody diagrarn correlations assuming the cooling channel surface is smooth. The correlations for the friction factors are given by

$$
\begin{array}{cccc}
f=\frac{64}{\operatorname{Re}_{C X_{A v g .}}} & \text { If } & R e_{C X_{A v g}}<2.2 \times 10^{3} \\
f=4 C_{1}\left[.0014+\frac{.125}{\left(\operatorname{Re} C X_{A v g .}\right)^{.32}}\right] & \text { If } & R e_{C X_{A v g .}}>2.2 \times 10^{3} \& \\
f=.0778 C_{1}\left(\operatorname{Re}_{\left.\left.C X_{A v g}\right)\right)^{-.1021}}\right. & \text { If } & R e_{C X_{A v g .}}<10^{4} \\
R e_{C X_{A v g .}}>10^{4}
\end{array}
$$

where

$$
C_{1}=\frac{C_{C}}{.023}=f(\text { station })
$$

Once the friction factors are determined, the viscous pressure drop between stations $n-1$ and $n$ is calculated using Darcy's law which is given by

$$
\left(\Delta P_{C S_{n-1, n}}\right)_{f}=\frac{f}{4 g_{c}}\left(\frac{\rho_{C S_{n}}+\rho_{C S_{n-1}}}{d_{C_{n}}+d_{C_{n-1}}}\right)\left(V_{C S_{n}}^{2}+V_{C S_{n-1}}^{2}\right) \Delta S_{n-1, n}
$$

and the momentum pressure drop is calculated using the following equation:

$$
\begin{aligned}
\left(\Delta P_{C S_{n-1, n}}\right)_{M}= & {\left[\frac{2}{\left(N A_{C}\right)_{n-1}+\left(N A_{C}\right)_{n}}\right] \frac{W_{C}^{2}}{g_{c}} } \\
& \cdot\left[\frac{1}{\left(\rho C S A_{C} N\right)_{n}}-\frac{1}{\left(\rho_{C} A_{C} N\right)_{n-1}}\right]
\end{aligned}
$$

An average value of variables between stations $n$ and $n-1$ are used to improve the accuracy. The static pressure at each station is calculated based on the viscous and momentum pressure drops and is given by

$$
P_{C S_{n}}=P_{C S_{n-1}}-\left[\left(\Delta P_{C S_{n-1, n}}\right)_{f}+\left(\Delta P_{C S_{n-1, n}}\right)_{M}\right]
$$

The reference and adiabatic wall enthalpies at the station are, respectively, calculated from the following equations [10]

$$
i_{C X_{n}}=0.5\left(i_{C S_{n}}+i_{C W_{n}}\right)+0.194\left(i_{C O_{n}}-i_{C S_{n}}\right)
$$


and

$$
i_{C A W_{n}}=i_{C S_{n}}+\left(P r_{C X}\right)^{1 / 3}\left(i_{C O_{n}}-i_{C S_{n}}\right)
$$

The adiabatic wall temperature is a function of the coolant static pressure and the adiabatic wall temperature and is evaluated using the GASP program [8]. Note that the Prandtl number in equation (17) is expressed by

$$
\operatorname{Pr}_{C X}=\frac{C_{p_{C X}} \mu_{C X}}{k_{C X}}
$$

where $C_{p_{C X}}, \mu_{C X}, k_{C X}=f\left(P_{C S}, i_{C X}\right)$.

To evaluate the coolant heat transfer coefficient the correlation given in references [13-15] is used. In this correlation the Nusselt number is given by

$$
\frac{N u}{N u_{r}}=0.023 R e^{0.8} \operatorname{Pr}^{0.4}
$$

where

$$
\begin{gathered}
N u_{r}=\psi^{-0.55} \\
\psi=1+\beta\left(T_{W}-T_{S}\right)
\end{gathered}
$$

and

$$
\beta=\left|\frac{1}{\rho} \frac{\partial \rho}{\partial T}\right|=\frac{1}{\rho} \frac{\left(\frac{\partial P}{\partial T}\right)_{\rho}}{\rho\left(\frac{\partial \dot{P}}{\partial \rho}\right)_{T}}
$$

Properties for the above correlation are based on the coolant static temperature $T_{C S}$, and static pressure $P_{C S}$. These properties are calculated using the GASP program [8], or the WASP program [9] if the coolant is water. It should also be noted that there are three coolant heat transfer coefficients and adiabatic wall temperatures. They are for the top, side, and bottom walls of the cooling channel. The variable heat transfer coefficient is due to the variable wall temperature in the cooling channel. The coolant reference and adiabatic wall enthalpies are also functions of wall temperature and are larger for the surface nodes closer to the 
bottom of the cooling channel.

Once the heat transfer coefficients and adiabatic wall temperatures for the hot gas and coolant are evaluated, the two-dimensional finite difference program discussed in reference [12 $]^{1}$ is used to re-evaluate the wall temperature distribution. Based on the revised wall temperature, new hot gas and coolant wall properties, heat transfer coefficients and adiabatic wall temperatures are calculated using equations (1) through (18). Again, a new wall temperature distribution based on the most recent heat transfer coefficients and adiabatic wall temperatures is calculated using the two dimensional finite difference program [12]. This procedure is repeated until the relative difference between the temperature distribution of two consecutive iterations becomes negligibly small. By performing similar calculations for all stations, the temperature profile for the entire engine is calculated. A complete flow chart of this numerical model is given in the Appendix.

Three assumptions are made in the present model:

1. Axial heat conduction through the engine wall is neglected, i.e., there is no heat conduction between two stations.

2. Radiation heat transfer between the hot gases and surfaces of the engine is not included in the present analysis.

3. Steady state flow and heat transfer.

\footnotetext{
${ }^{1}$ The computer program discussed in [12] has been specifically developed for a rocket thrust chamber and nozzle two-dimensional configuration as shown in Figure 1. Because of the symmetry of the configuration, computations are performed for only one cell (see Figure 3 ). In this program the thermal conductivities can be functions of temperature and it implements a successive overrelaxation formula for a quick convergence. The resuling output of the program consists of the nodal temperature distribution, heat transfer to the coolant and heat transfer from the hot gas.
} 
A discussion regarding the validity of the above assumptions is presented in the next section.

\section{Results and Discussion}

A computer code based on the numerical model introduced in the previous section has been developed. A complete description of the code is presented in [16] and it is used to determine the temperature distribution and heat transfer characteristics of a Liquid Oxygen/Kerosene rocket engine (engine 700). The engine has the following specifications:

Fuel

Oxident

Coolant

Chamber stagnation pressure $P_{G O}$

Coolant stagnation pressure $P_{C O}$

Fuel weight flow rate

Coolant weight flow rate

Fuel/Oxident percentage

Coolant stagnation temperature

Number of cooling channels
Kerosene (RP-1)

$\mathrm{LO}_{2}$

$\mathrm{LO}_{2}$

2000 psi

$5000 \mathrm{psi}$

$58.023 \mathrm{lb} / \mathrm{sec}$

$39.2 \mathrm{lb} / \mathrm{sec}$

$26.316 \%$

$150^{\circ} \mathrm{R}$

100

This engine is subdivided into 22 stations. Table 1 shows dimensions of the engine and some thermal characteristics at each station (see Figure 3 for notation). Note that dimensions given in Table 1 are in inches. There are two variables that remain constant along the engine. These varables are: $C_{C}=5.36 \times 10^{-4}$ and $D C I N=0.035$ in. The outer surface radiates to space and its emissivity is 0.9 . 
The thermal conductivities of wall materials, i.e., nickel and copper are functions of temperature and are given by Figures 4 and 5 [19], and no coating is used in the engine. Tables 2, 3 and 4 show the resulting temperature distribution for stations 1, 9(throat) and 22 respectively. The previous model at NASA Lewis Research Center used a lumped temperature assumption in the radial and circumferential directions while the present model allows temperature variations in all three directions. Close examination of the temperature distributions given in Tables 2, 3 and 4 reveals that the temperature gradient is relatively large in radial direction, especially for station 9. Hence, the uniform wall temperature assumption in the radial and circumferential direction used in the previous NASA model is not a good assumption for the engine considered here. This may also be true for any other high pressure thrust chamber.

Figures 6 and 7 show temperatures of the inner and outer surfaces and the coolant along the engine for chamber pressures of 2000 and 1200 psi respectively. The resulting lumped wall (1-Dimensional model) temperatures along radial and circumferntial directions are also given in Figures 6 and 7. As can be seen from these figures, the lumped temperature results are very close to those of the inner wall at the early stations; however, in the later stations the difference becomes larger which might be due to the large temperature gradient. For engines with lower chamber pressures, the temperature gradient is small; hence, the lumped temperature assumption will provide reasonable results.

Despite the improvements of the present code over the existing model, some items remain that should be considered in future modifications of the present model. One item is the axial heat conduction through the cooling channel wall. By looking at the wall temperature distribution along the longitudinal direction 
given in Figures 6 and 7, one can see that there is a large wall temperature gradient in the axial direction. Hence, some heat is transferred by conduction between two neighboring stations. This heat transfer can roughly be estimated through

$$
q_{n-1, n}=\frac{-k A_{n-1, n}}{\Delta S_{n-1, n}}\left(T_{n-1}-T_{n}\right)
$$

where $q_{n-1, n}, A_{n-1, n}$ and $\Delta S_{n-1, n}$ are the heat conduction, contact area and distance between stations $n-1$ and $n$ respectively.

Another item which needs serious consideration is the radiative heat transfer from the hot gas to the surface and from surface to surface. The chamber temperature for the engine considered here reaches $3800^{\circ} \mathrm{R}$ while the wall temperature is of the order of $1200^{\circ} \mathrm{R}$. With this temperature range, radiation becomes a significant means of heat transfer. A rough estimate of the radiative heat transfer from the hot gas to the surface can be obtained from [17-18]

$$
q_{G \rightarrow S}=K_{t}\left(1-\omega_{0}\right) \overline{G S} \sigma\left(T_{G}^{4}-T_{S}^{4}\right)
$$

where $T_{G}$ and $T_{S}$ are gas and surface temperatures respectively, $K_{t}$ and $\omega_{0}$ are gas total extinction coefficient and albedo for scattering, $\overline{G S}$ total exchange factor from gas to surface and $\sigma$ is the Stefan Boltzmann constant. Besides radiative transfer between the hot gas and surface, there is some radiative transfer from the high temperature surface to the lower temperature surface.

Finally, most rocket engines perform for a relatively short period of time and, for maneuvering purposes, the fuel and coolant flow rate vary during this. Therefore, they never reach a steady state condition. A transient thermal analysis, although a bit ambitious, would make the present model capable of simulating actual rocket performance. 


\section{Concluding Remarks}

A numerical model for three dimensional thermal analysis of rocket engines has been developed. This model allows temperature variation along three directions: axial, radial and circumferential. The numerical results presented show that there is a large temperature gradient in the axial direction for engines with a high chamber pressure. This makes the lumped temperature assumption used in the previous model invalid for these types of engines.

Experimental results exist for the engine analyzed in this paper. However, a comparison of the experimental and numerical results is not possible for two reasons. First, the engine only ran for five seconds during the experiment and did not reach a steady state condition. The fuel weight flow rate varied during this period. The second reason is that the exact position of the thermocouples used for the experiment is not known. A more carefully controlled experiment is needed to make a comparison with the numerical results meaningful.

The numerical model needs to be modified further to incorporate a transient analysis, effects of axial conduction and chamber radiation. Efforts are presently under way to include these items into the numerical model. 


\section{Appendix}

Flow chart for three dimensional thermal analysis of rocket thrust chamber and nozzle.

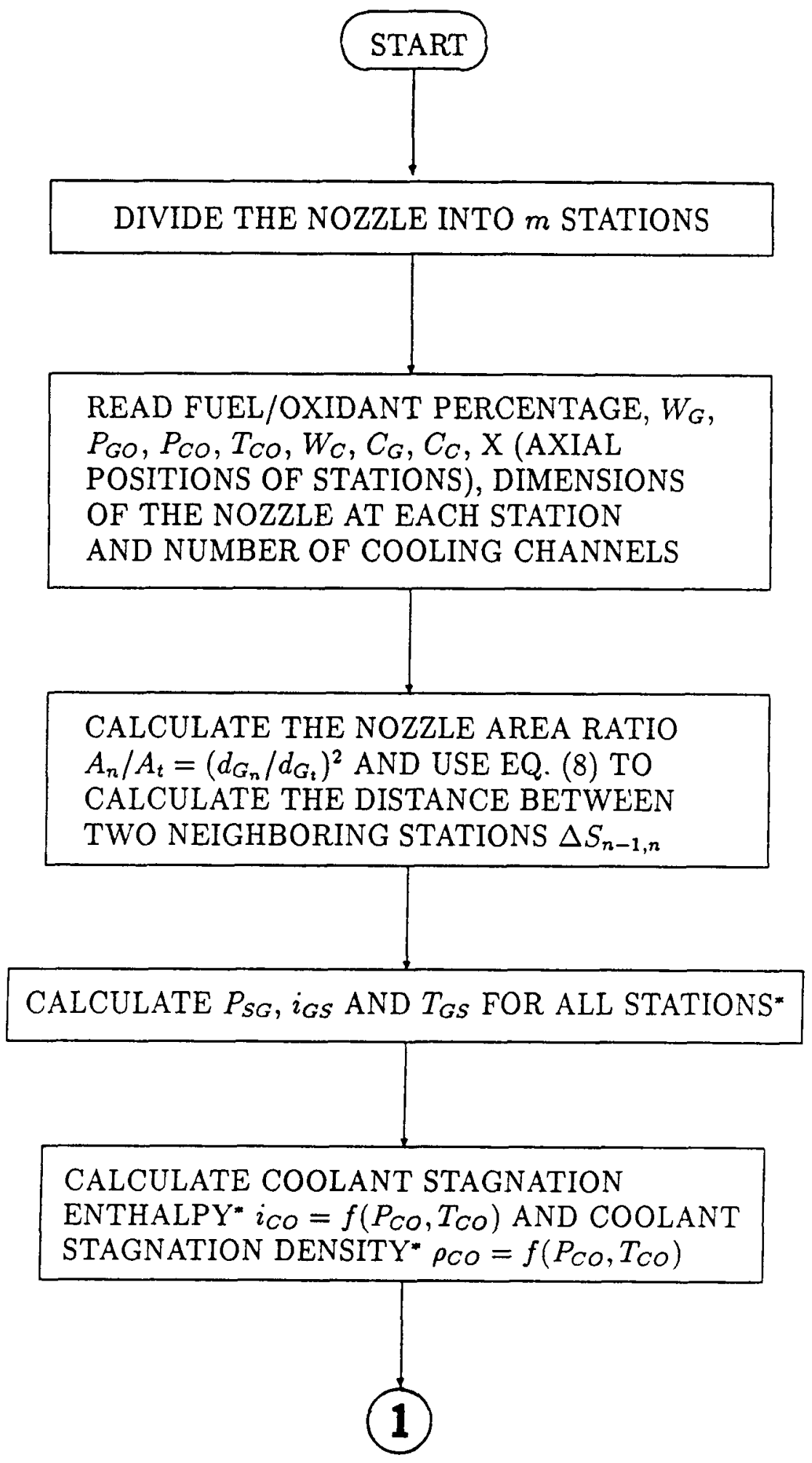




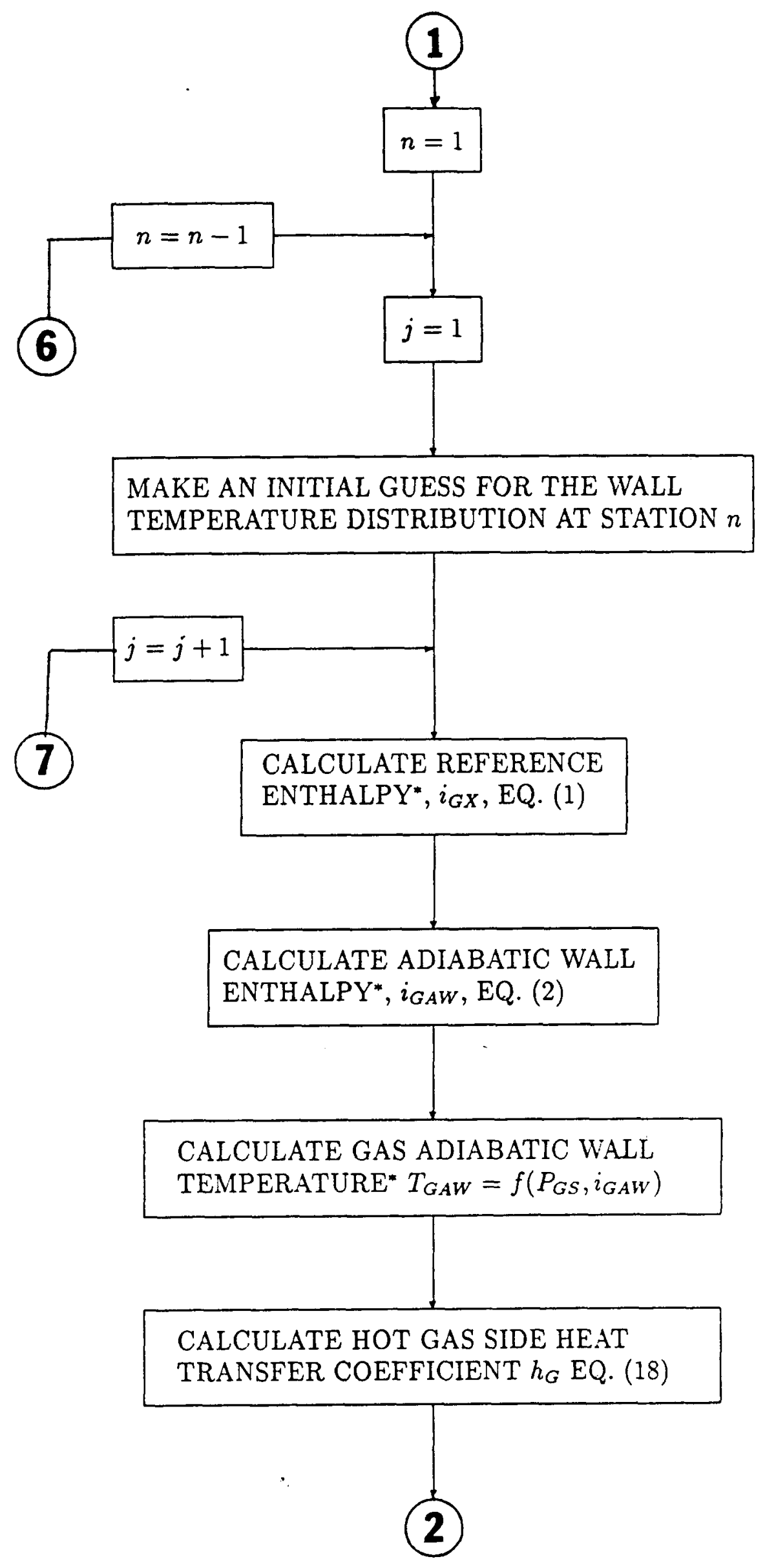




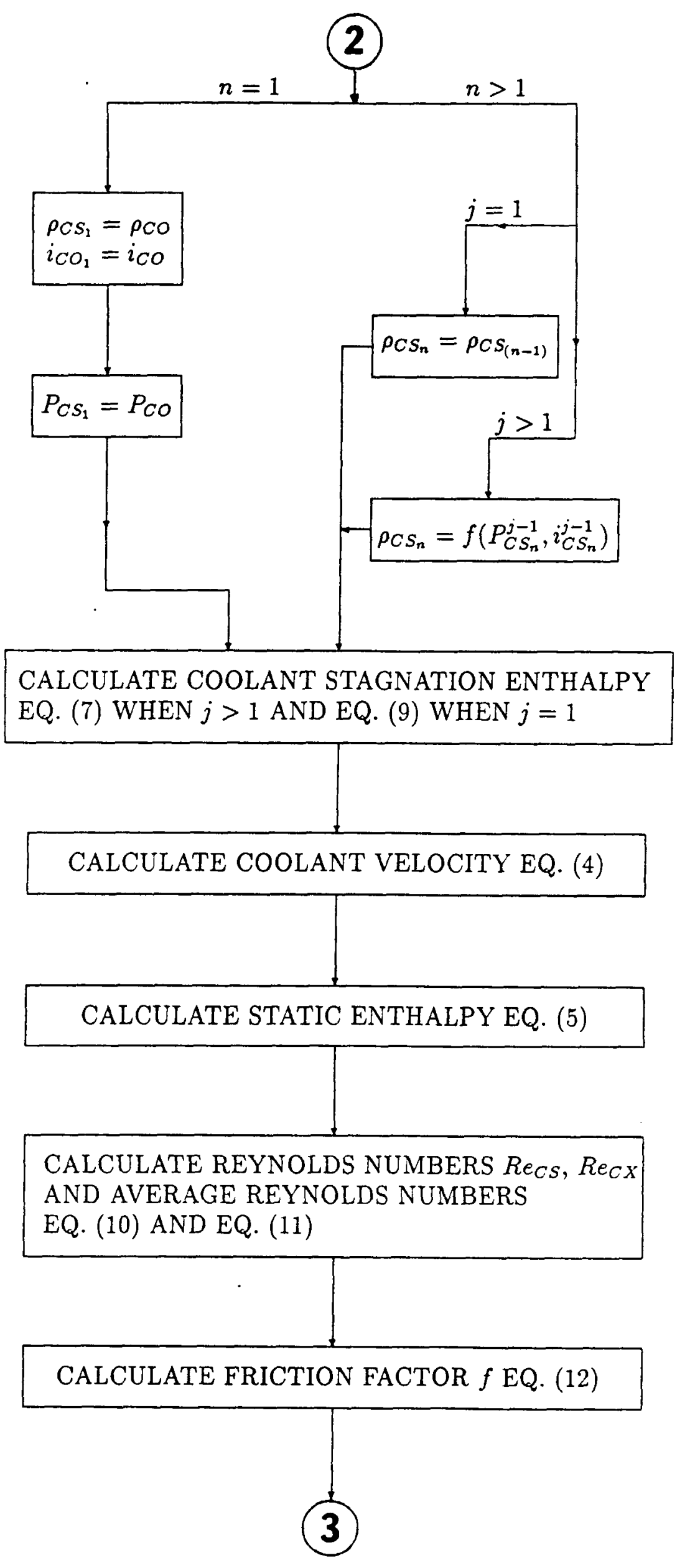




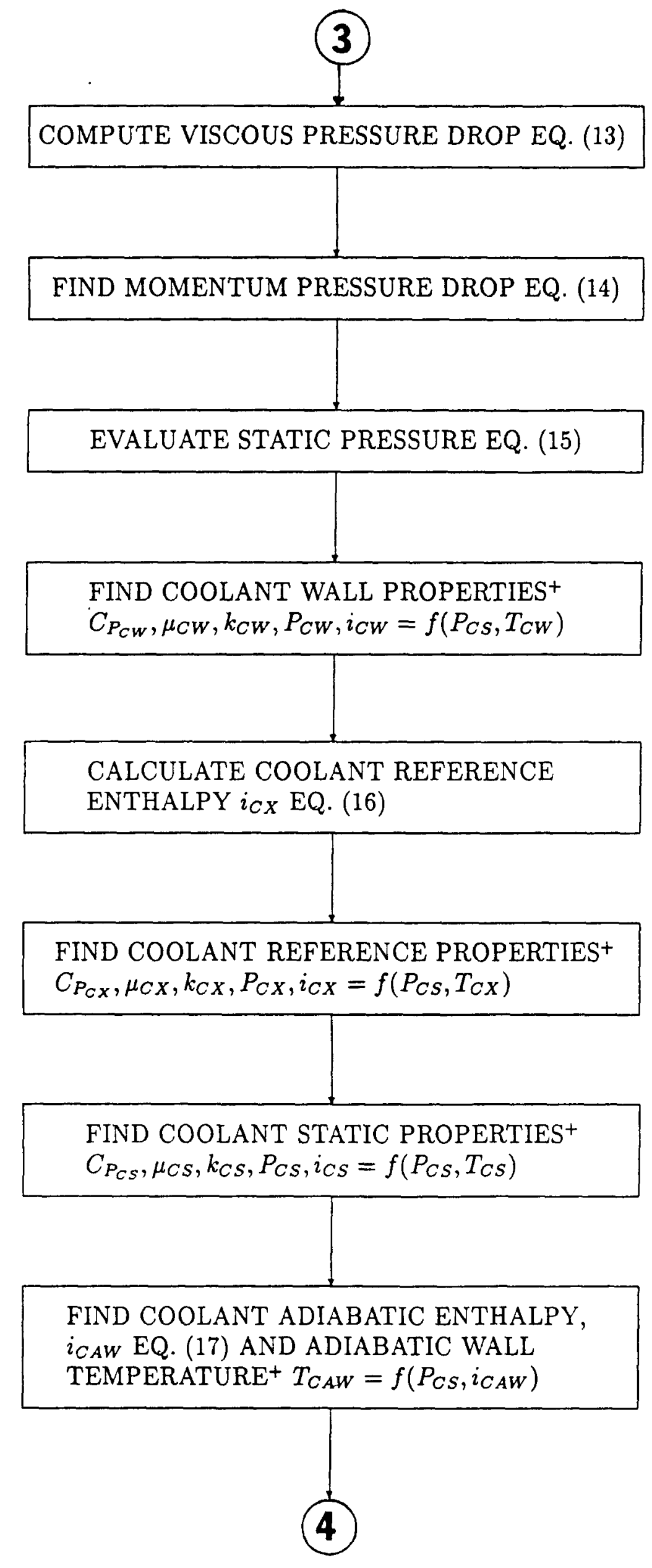




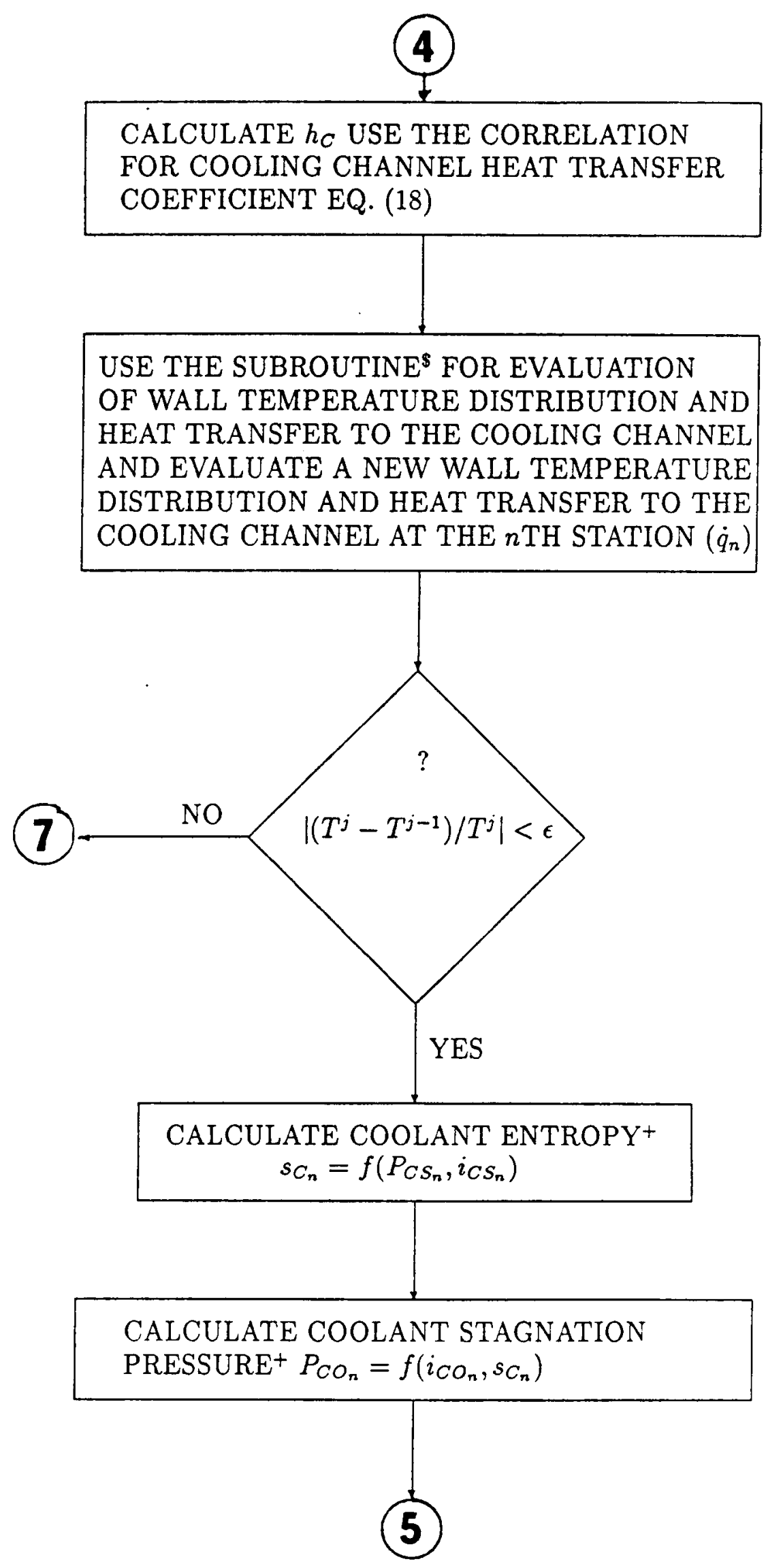




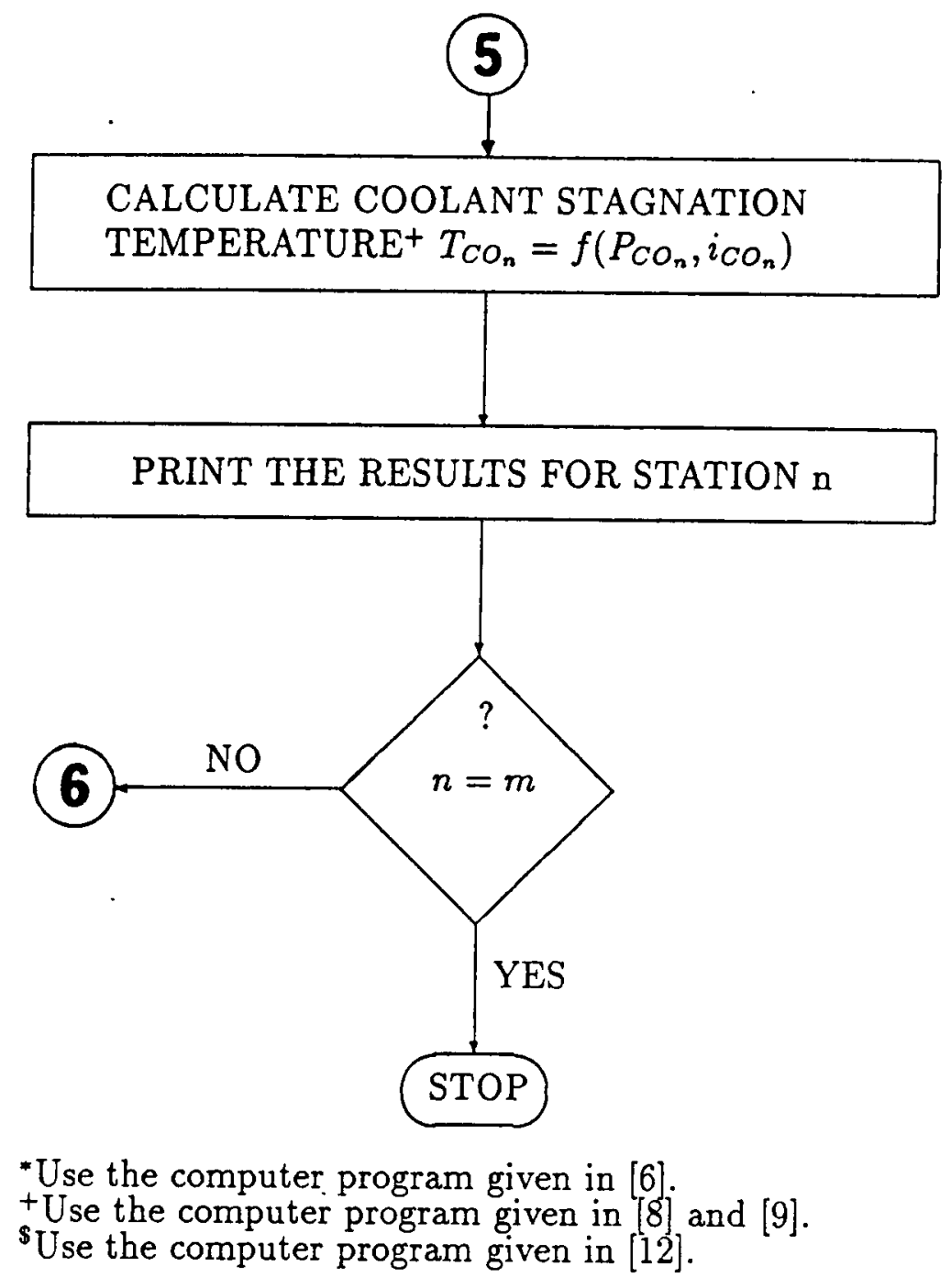




\section{References}

1. Gaski, J. D. and Lewis, D. R., Chrysler/System Improve Numerical Differencing Analyzer: CINDA/SINDA 3 G, Chrysler Corp. Space Div., Rept. TN-AP-G7-287, Oct. 1967.

2. Bathe, K. J., ADINAT-A Finite Element Program for Automatic Numerical Dynamic Incremental Nonlinear Analysis of Temperature, Rep. 824485. Acoustics and Vibration Laboratory, Mechanical Engineering Department, Massachusetts Institute of Technology, Cambridge, Massachusetts, Dec. 1978.

3. MARC User Information Manuals, MARC Analysis research Corporation, Palo Alto, California.

4. DeSalvo, G. J. and Swanson, J. A., ANSYS User's Manual, Swanson Analysis Systems, Inc., Houston, Pennsylvania, July 1979.

5. McCormic, C. W. (Editor), NASTRAN User's Manual, NASA SP-222(01) 1972

6. Gordon, S. and McBride, B. J., Computer Program for Calculation of Complex Chemical Equilibrium Compositions, Rocket Performance, Incident and Refiection Shocks, and Chapman-Jouquet Detonations, NASA SP-273, 1971.

7. Gordon, S., McBride, B. J. and Zeleznik, F. J., Computer Program for Calculation of Complex Chemical Equilibrium Compositions and Applications Supplement I - Transport Properties, NASA TM-86885, Oct. 1984.

S. Hendricks, R. C., Baron, A. K. and Peller, I. C., GASP - A Computer Code for Calculating the Thermodynamic and Transport Properties for Ten Fluids: Parahydrogen, Helium, Neon, Methane, Nitrogen, Carbon Monoxide, Oxygen, Fluorine, Argon, and Carbon Dioxide, NASA TN D-7808, Feb. 1975

9. Hendricks, R. C., Peller, I. C. and Baron, A. K., WASP - A Flexible Fortran IV Computer Code for Calculating Water and Steam Properties, NASA TN D-7391, Nov. 1973.

10. Eckert, E. R. G. and Drake, R. M., Analysis of Heat and Mass Transfer, McGraw-Hill Book Company, 1972.

11. Bartz, D. R., Turbulent Boundary-Layer Heat Transfer from Rapidly Accelerating Flow of Rocket Combustion Gases and of Heated Air, Advances in Heat Transfer, pp. 2-108, 1965.

12. Naraghi, M. H. N., A Two-Dimensional Finite Difference Program for Thermal Analysis of Rocket Thrust Chambers, NASA TM 100191, Sept. 1987. 
13. Kumakawa, A., Niino, M., Hendricks, R. C., Giarratano, P. J. and Arp, V. D., Volume-Energy Parameters for Heat Transfer to Supercritical Fluids, 15Th. International Symposium on Space Technology and Science, Tokyo, Japan, May 19-23, 1986, Proceeding Volume 1, A87-2276 13-12, Tokyo, AJNE Publishing Inc., pp. 389-399, 1986.

14. Niino, M., Kumakawa, A., Yatsuyanagi, N. and Suzuki, A., Heat Transfer Characteristics of Liquid Hydrogen as a Coolant for the LO2/LH2 Rocket Thrust Chamber with the Channel Wall Construction, 18Th. AIAA/SAE/ASME: Joint Propulsion Conference, Cleveland, Ohio, June 21-23, 1982, AIAA paper 82-1107.

15. Hendricks, R. C., Niino, M., Kumakawa, A., Yeroshenko, V. M., Yaskin, L. A., Braun, M. J. and Moullen, R. L., Friction Factors and Heat Transfer Coefficients for Hydrogen Systems Operating at Supercritical Pressures, Proceeding of Beijing International Symposium on Hydrogen Systems, Beijing, China, May 7-11, 1985.

16. Naraghi, M.H.N., RTE - A Computer Code For Three Dimensional Rocket Thermal Evaluation, Manhattan College Report prepared for NASA Lewis Research Center, Grant No. NAG 3-759, 1988.

17. Siegel, R and Howell, J. R., Thermal Radiation Heat Transfer, 2nd Edition, McGraw-Hill Book Company, New York, 1981.

18. Hottel, H. C. and Sarofim, A. F., Radiative Transfer, McGraw-Hill Book Company, New York, 1967.

19. Touloukian, Y.S., Thermophysiccl Properties of High Temperature Solid Materials, Thermophysical Properties Center, Purdue University, 1967. 
Table 1: Parameters of thrust chamber and nozzle at different stations.

(Dimensions are in inches)

\begin{tabular}{|c|cccccc|}
\hline Station & $X$ & $D G$ & $C C W$ & $C C H$ & $T H K N S$ & $C_{G}$ \\
\hline 1 & 7. & 6.26 & 0.06 & 0.191 & 0.462 & 0.0234 \\
2 & 5.024 & 5.2 & 0.06 & 0.186 & 0.423 & 0.0212 \\
3 & 3.5 & 4.382 & 0.06 & 0.185 & 0.42 & 0.0185 \\
4 & 2. & 3.58 & 0.06 & 0.187 & 0.422 & 0.0168 \\
5 & 1. & 3.042 & 0.04 & 0.16 & 0.395 & 0.0162 \\
6 & 0.5 & 2.778 & 0.04 & 0.146 & 0.381 & 0.0143 \\
7 & 0.337 & 2.688 & 0.04 & 0.135 & 0.37 & 0.0144 \\
8 & 0.237 & 2.642 & 0.04 & 0.124 & 0.359 & 0.0152 \\
9 & 0. & 2.6 & 0.04 & 0.095 & 0.33 & 0.0165 \\
10 & -0.274 & 2.656 & 0.04 & 0.087 & 0.322 & 0.0168 \\
11 & -0.506 & 2.7 & 0.04 & 0.077 & 0.312 & 0.0192 \\
12 & -0.906 & 2.924 & 0.04 & 0.06 & 0.295 & 0.0219 \\
13 & -1.306 & 3.092 & 0.04 & 0.066 & 0.301 & 0.022 \\
14 & -1.506 & 3.178 & 0.04 & 0.069 & 0.304 & 0.022 \\
15 & -1.906 & 3.344 & 0.04 & 0.071 & 0.306 & 0.0225 \\
16 & -2.906 & 3.77 & 0.04 & 0.078 & 0.313 & 0.023 \\
17 & -3.506 & 4.022 & 0.06 & 0.077 & 0.312 & 0.023 \\
18 & -4.906 & 4.468 & 0.06 & 0.095 & 0.33 & 0.023 \\
19 & -5.906 & 4.666 & 0.06 & 0.112 & 0.347 & 0.023 \\
20 & -6.906 & 4.774 & 0.06 & 0.112 & 0.347 & 0.023 \\
21 & -7.572 & 4.8 & 0.06 & 0.11 & 0.345 & 0.023 \\
22 & -10. & 4.8 & 0.06 & 0.11 & 0.345 & 0.023 \\
\hline
\end{tabular}


Table 2: Temperature distribution $\left({ }^{\circ} R\right)$ at station 1.

\begin{tabular}{|c|ccccccc|}
\cline { 2 - 8 } \multicolumn{1}{c|}{} & \multicolumn{6}{c|}{ RADIANS FROM CENTERLINE OF CHANNEL } \\
\hline RADIUS (in) & 0.03141 & 0.02410 & 0.01679 & 0.00948 & 0.00632 & 0.00316 & 0.00000 \\
\hline 3.5560 & 221.16 & 221.12 & 221.02 & 220.91 & 220.87 & 220.85 & 220.84 \\
3.5060 & 221.31 & 221.23 & 221.04 & 220.82 & 220.75 & 220.71 & 220.69 \\
3.4560 & 222.04 & 221.80 & 221.16 & 220.39 & 220.14 & 219.98 & 219.92 \\
3.4060 & 224.72 & 223.95 & 221.81 & 218.86 & 217.76 & 217.01 & 216.75 \\
3.3560 & 233.84 & 231.86 & 225.83 & 215.20 & 207.78 & 203.79 & 202.53 \\
3.3178 & 243.40 & 241.37 & 235.37 & 225.77 & \multicolumn{3}{|c|}{} \\
3.2796 & 263.25 & 260.94 & 254.06 & 242.82 & & COOLING & \\
3.2414 & 295.26 & 292.54 & 284.25 & 270.18 & & CHANNEL & \\
3.2032 & 342.21 & 339.35 & 330.28 & 313.28 & & & \\
3.1650 & 405.61 & 403.93 & 398.86 & 389.60 & 402.16 & 406.84 & 408.12 \\
3.1562 & 421.65 & 420.25 & 416.43 & 412.42 & 417.54 & 420.72 & 421.75 \\
3.1475 & 438.18 & 437.02 & 434.13 & 432.22 & 434.49 & 436.36 & 437.03 \\
3.1388 & 455.15 & 454.14 & 451.80 & 450.69 & 451.87 & 453.01 & 453.46 \\
3.1300 & 472.52 & 471.56 & 469.39 & 468.50 & 469.39 & 470.30 & 470.67 \\
\hline
\end{tabular}


Table 3: Temperature distribution at station 9(throat).

\begin{tabular}{|c|ccccccc|}
\cline { 2 - 8 } \multicolumn{1}{c|}{} & \multicolumn{7}{c|}{ RADIANS FROM CENTERLINE OF CHANNEL } \\
\hline RADIUS (in) & 0.03141 & 0.02410 & 0.01679 & 0.00948 & 0.00632 & 0.00316 & 0.00000 \\
\hline 1.6300 & 445.83 & 445.83 & 445.83 & 445.83 & 445.83 & 445.82 & 445.82 \\
1.5800 & 445.84 & 445.84 & 445.83 & 445.82 & 445.82 & 445.81 & 445.81 \\
1.5300 & 446.04 & 446.01 & 445.92 & 445.81 & 445.71 & 445.64 & 445.61 \\
1.4800 & 448.38 & 448.05 & 447.12 & 445.76 & 444.40 & 443.41 & 443.06 \\
1.4300 & 477.19 & 474.38 & 465.80 & 450.96 & 426.24 & 412.99 & 408.81 \\
1.4110 & 504.65 & 502.54 & 496.36 & 486.62 & & & \\
1.3920 & 558.36 & 556.06 & 549.23 & 538.01 & & COOLING & \\
1.3730 & 641.91 & 639.14 & 630.78 & 616.72 & & CHANNEL \\
1.3540 & 763.19 & 760.31 & 751.22 & 734.35 & & & \\
1.3350 & 926.10 & 926.25 & 927.01 & 929.35 & 973.30 & 992.40 & 997.89 \\
1.3262 & 1002.06 & 1002.96 & 1006.17 & 1013.56 & 1028.32 & 1038.54 & 1042.02 \\
1.3175 & 1076.43 & 1077.36 & 1080.31 & 1085.55 & 1092.04 & 1097.06 & 1098.89 \\
1.3087 & 1149.03 & 1149.81 & 1152.09 & 1155.60 & 1159.20 & 1161.98 & 1163.01 \\
1.3000 & 1220.29 & 1220.99 & 1222.99 & 1225.92 & 1228.76 & 1230.91 & 1231.71 \\
\hline
\end{tabular}


Table 4: Temperature distribution at station 22 .

\begin{tabular}{|c|ccccccc|}
\cline { 2 - 8 } \multicolumn{1}{c|}{} & \multicolumn{7}{c|}{ RADIANS FROM CENTERLINE OF CHANNEL } \\
\hline RADIUS (in) & 0.03141 & 0.02410 & 0.01679 & 0.00948 & 0.00632 & 0.00316 & 0.00000 \\
\hline 2.7450 & 869.30 & 869.25 & 869.13 & 868.98 & 868.89 & 868.83 & 868.81 \\
2.6950 & 869.73 & 869.61 & 869.29 & 868.89 & 868.67 & 868.52 & 868.46 \\
2.6450 & 872.20 & 871.65 & 870.17 & 868.18 & 867.02 & 866.21 & 865.91 \\
2.5950 & 884.41 & 882.13 & 875.52 & 865.38 & 858.03 & 852.75 & 850.85 \\
2.5450 & 939.58 & 933.48 & 914.10 & 877.00 & 803.89 & 766.13 & 754.57 \\
2.5230 & 957.83 & 952.86 & 938.27 & 915.86 & & & \\
2.5010 & 995.05 & 990.63 & 977.55 & 956.39 & & COOLING & \\
2.4790 & 1049.73 & 1045.61 & 1032.95 & 1010.88 & & CHANNEL & \\
2.4570 & 1121.36 & 1118.15 & 1107.72 & 1086.76 & & & \\
2.4350 & 1207.01 & 1206.33 & 1204.84 & 1204.56 & 1236.81 & 1249.62 & 1253.25 \\
2.4262 & 1242.25 & 1242.30 & 1243.28 & 1248.95 & 1263.71 & 1272.92 & 1275.90 \\
2.4175 & 1277.70 & 1278.22 & 1280.50 & 1286.94 & 1295.09 & 1301.16 & 1303.31 \\
2.4087 & 1313.06 & 1313.82 & 1316.64 & 1322.78 & 1328.31 & 1332.65 & 1334.25 \\
2.4000 & 1348.17 & 1349.00 & 1351.96 & 1357.89 & 1362.71 & 1366.50 & 1367.92 \\
\hline
\end{tabular}



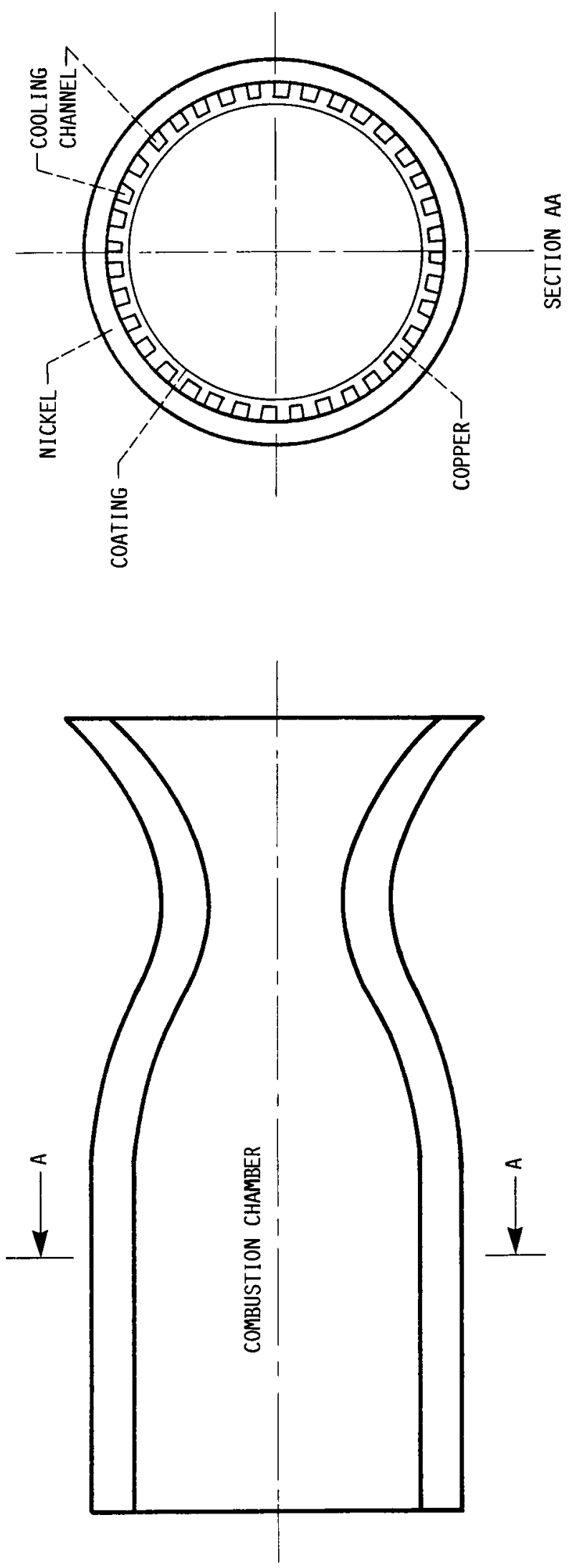

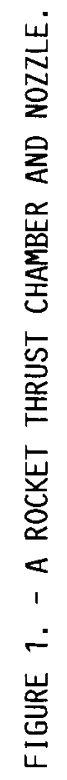




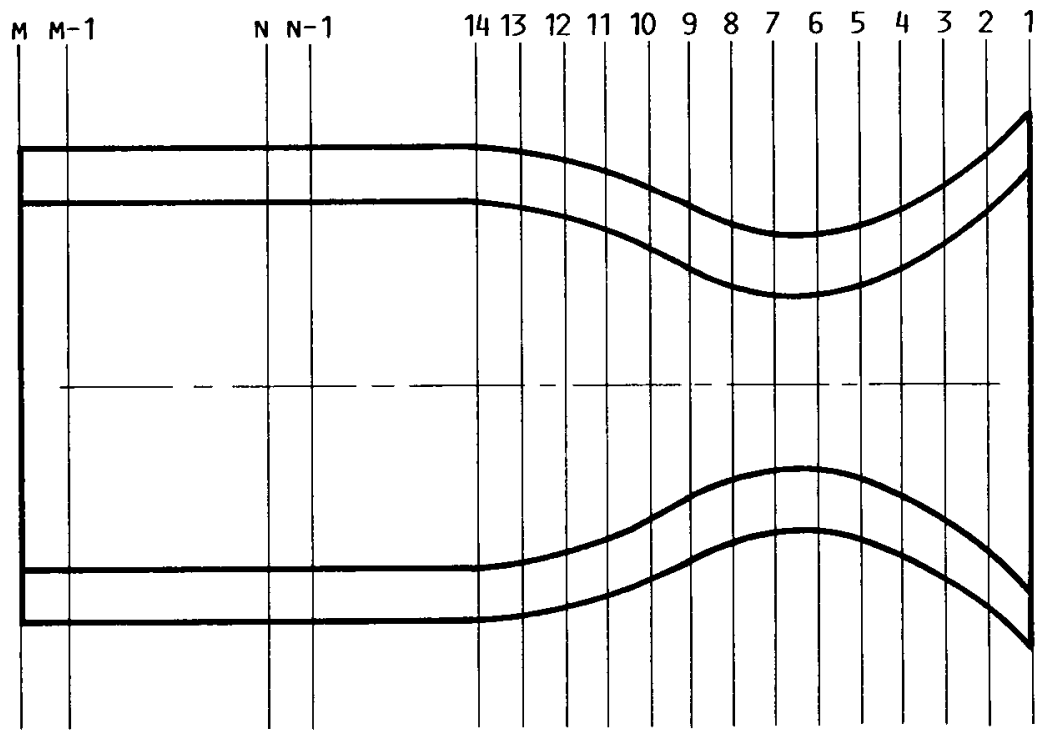

FIGURE 2. - A ROCKET THRUST CHAMBER SUBDIVIDED INTO A NUMBER OF STATIONS.

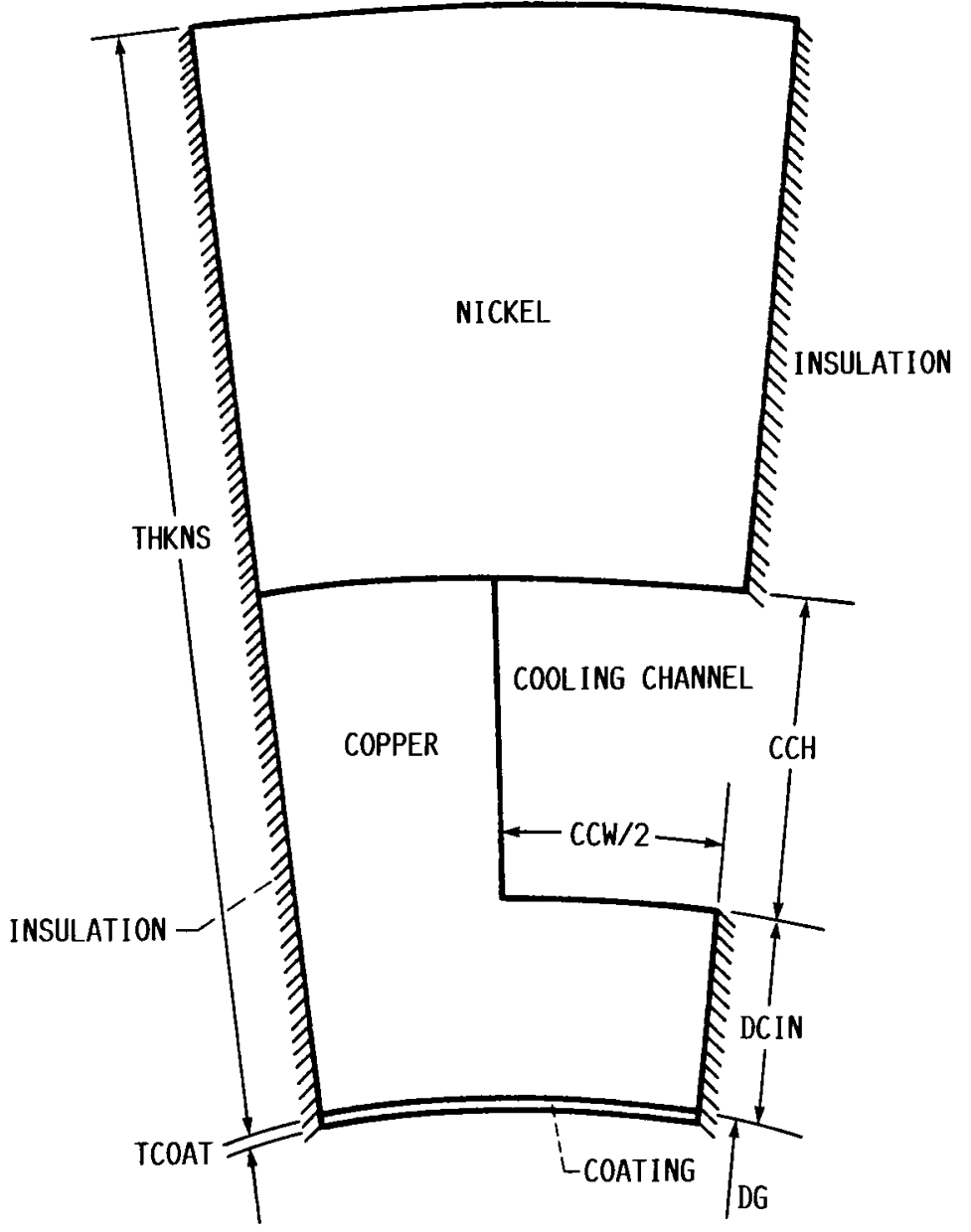

FIgURE 3. - A HALF COOLING CHANNEL CELL. 


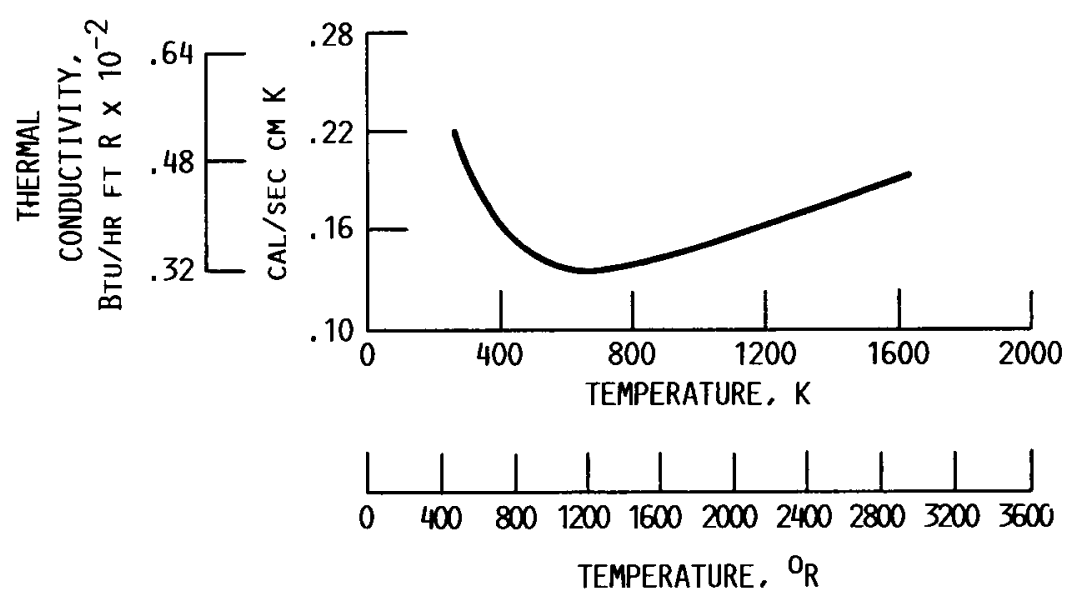

FIGURE 4. - THERMAL CONDUCTIVITY OF NICKEL.

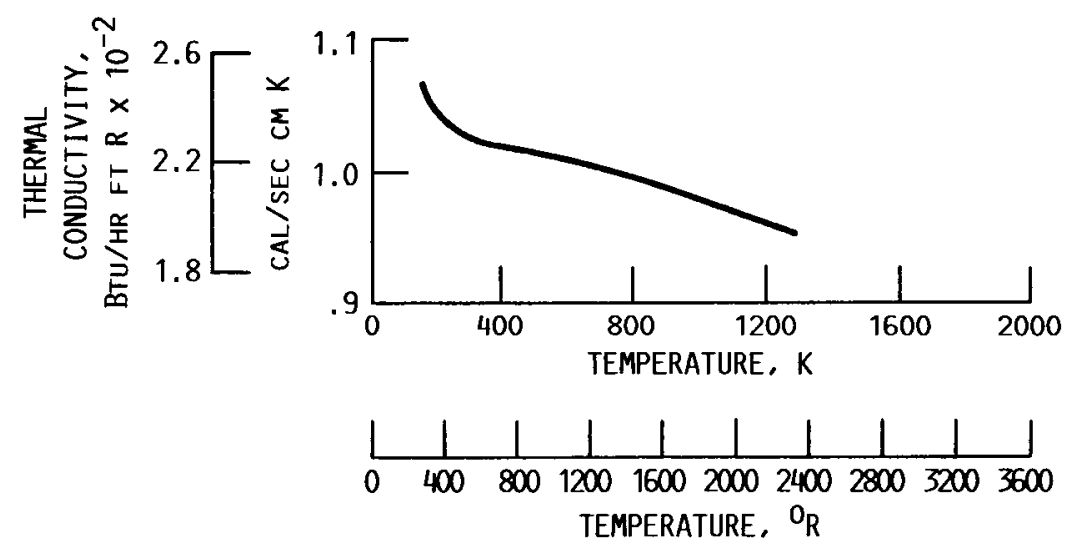

FIGURE 5. - THERMAL CONDUCTIVITY OF COPPER. 


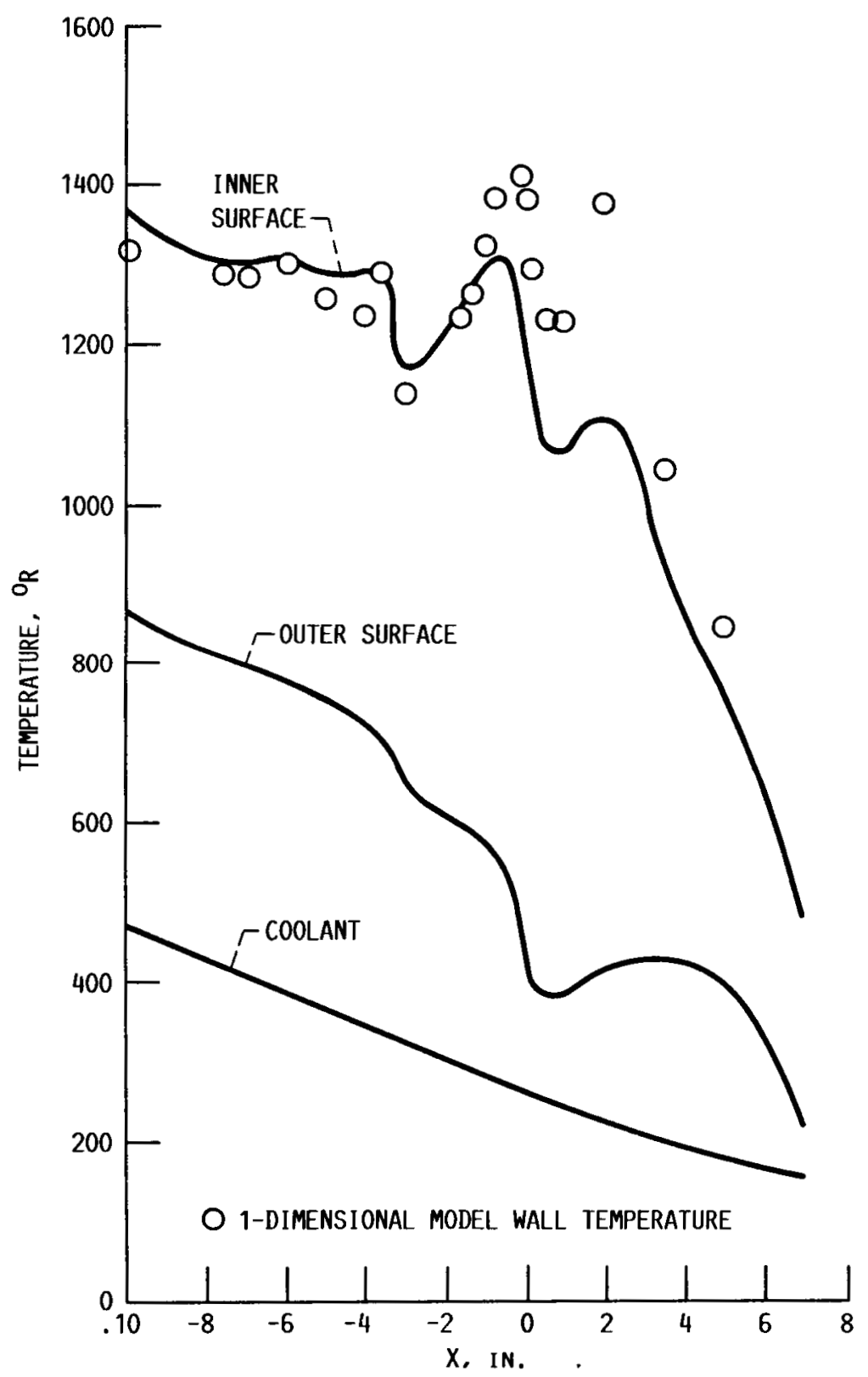

FIGURE 6. - INNER AND OUTER WALL SURFACE AND COOLANT TEMPERATURE WHEN $\mathrm{P}_{\mathrm{GO}}=2000$ PSI AND $\mathrm{P}_{\mathrm{CO}}=5000 \mathrm{PSI}$. 


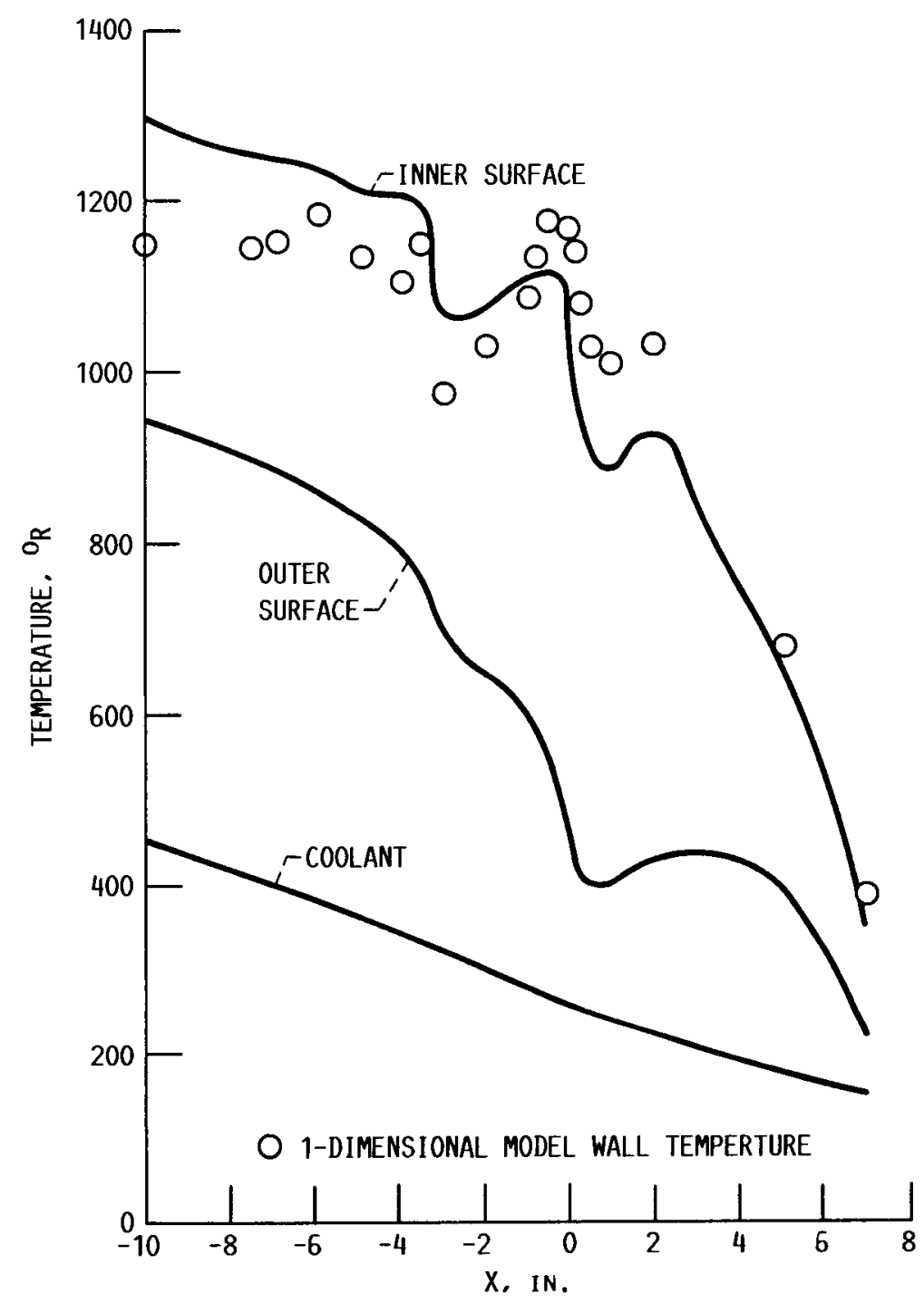

FIGURE 7. - INNER AND OUTER WALL SURFACE AND COOLANT TEMPERATURE WHEN $\mathrm{P}_{\mathrm{GO}}=1200$ PSI AND $\mathrm{P}_{\mathrm{CO}}=3200$ PSI. 


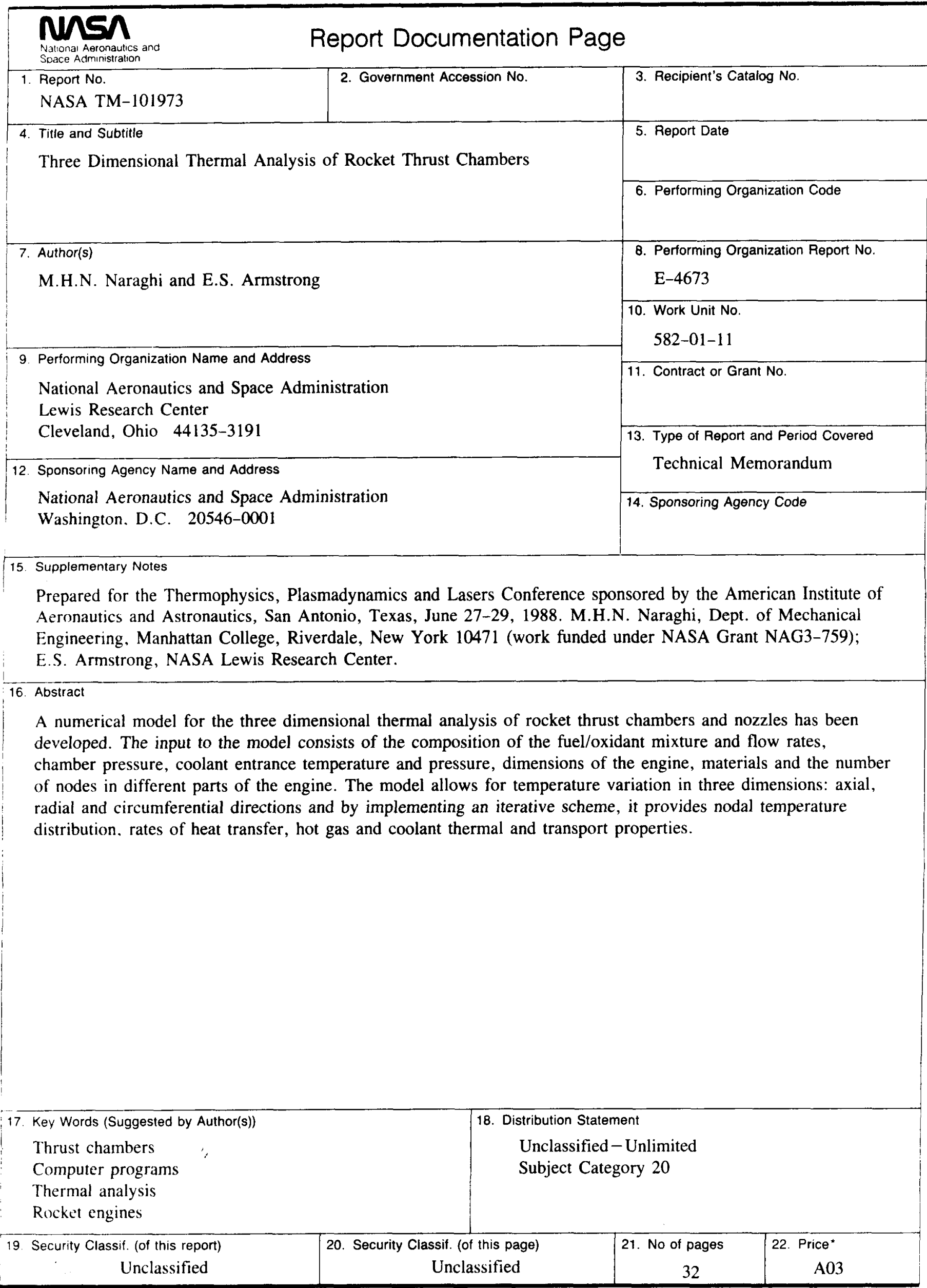

